\title{
Peroxidase Enzymes Regulate Collagen Extracellular Matrix Biosynthesis
}

\author{
Mark 0. DeNichilo, ${ }^{\star}$ Vasilios Panagopoulos, ${ }^{*}$ Timothy E. Rayner, ${ }^{\dagger}$ Romana A. Borowicz, ${ }^{\ddagger}$ John E. Greenwood, ${ }^{\S}$ and \\ Andreas Evdokiou*
}

\begin{abstract}
From the Breast Cancer Research Unit,* Discipline of Surgery, the Mesenchymal Stem Cell Laboratory, ${ }^{\ddagger}$ School of Medical Sciences, Faculty of Health Sciences, and the Center for Personalized Cancer Medicine, ${ }^{\top}$ The University of Adelaide, Adelaide, South Australia; the Paramedic Unit, ${ }^{\dagger}$ Flinders Clinical Effectiveness, School of Medicine, Flinders University, Bedford Park, South Australia; and the Adult Burn Centre, ${ }^{\S}$ Royal Adelaide Hospital, Adelaide, South Australia, Australia
\end{abstract}

Accepted for publication

January 21, 2015 .

Address correspondence to Mark O. DeNichilo, Ph.D., or Andreas Evdokiou, Ph.D., Basil Hetzel Research Institute, The Queen Elizabeth Hospital, 27a Woodville Rd, Woodville, SA 5011, Australia. E-mail: mark. denichilo@adelaide.edu.au or andreas.evdokiou@ adelaide. edu.au.

\begin{abstract}
Myeloperoxidase and eosinophil peroxidase are heme-containing enzymes often physically associated with fibrotic tissue and cancer in various organs, without any direct involvement in promoting fibroblast recruitment and extracellular matrix (ECM) biosynthesis at these sites. We report herein novel findings that show peroxidase enzymes possess a well-conserved profibrogenic capacity to stimulate the migration of fibroblastic cells and promote their ability to secrete collagenous proteins to generate a functional ECM both in vitro and in vivo. Mechanistic studies conducted using cultured fibroblasts show that these cells are capable of rapidly binding and internalizing both myeloperoxidase and eosinophil peroxidase. Peroxidase enzymes stimulate collagen biosynthesis at a post-translational level in a prolyl 4-hydroxylase-dependent manner that does not require ascorbic acid. This response was blocked by the irreversible myeloperoxidase inhibitor 4-amino-benzoic acid hydrazide, indicating peroxidase catalytic activity is essential for collagen biosynthesis. These results suggest that peroxidase enzymes, such as myeloperoxidase and eosinophil peroxidase, may play a fundamental role in regulating the recruitment of fibroblast and the biosynthesis of collagen ECM at sites of normal tissue repair and fibrosis, with enormous implications for many disease states where infiltrating inflammatory cells deposit peroxidases. (Am J Pathol 2015, 185: 1372-1384; http://dx.doi.org/10.1016/j.ajpath.2015.01.013)
\end{abstract}

Ascorbic acid (AA) has long been recognized as an essential cofactor required for collagen homeostasis, with long-term ascorbate dietary deficiency leading to the inadequate connective tissue renewal characteristic of scurvy. ${ }^{1}$ AA increases the secretion of collagen proteins by promoting efficient hydroxylation of peptidyl proline, leading to the assembly of a stabilized procollagen triple helical structure. ${ }^{2}$ Without hydroxylation, unfolded procollagen is thermally unstable and is retained within the cell and degraded. ${ }^{3}$ Prolyl 4hydroxylase $(\mathrm{P} 4 \mathrm{H})$ is the iron-containing enzyme responsible for catalyzing hydroxylation of procollagen within the cell. AA is thought to act as an electron donor that maintains the iron within the $\mathrm{P} 4 \mathrm{H}$ molecule in the $\mathrm{Fe}^{2+}$ state, thus enabling the enzyme to repeatedly hydroxylate proline residues. ${ }^{4}$ Unlike humans, mice are capable of synthesizing AA in the liver. By genetically deleting key genes responsible for the production of AA in mice, two recent studies concluded that collagen biosynthesis during both tumor development and renal fibrosis proceeds in the absence of AA, suggesting that alternative, yet unidentified, electron donor sources likely exist. These sources substitute for the requirement of AA in situations where a rapid escalation in collagen biosynthesis is a defining feature. . $^{5,6}$

Myeloperoxidase (MPO) and eosinophil peroxidase (EPO) are heme-containing enzymes whose functional involvement in human health has mainly been studied in the context of providing a mechanism for oxidative defense against invading bacteria and other pathogenic microorganisms. ${ }^{7}$

\footnotetext{
Supported in part by The Hospital Research Foundation and Australian Breast Cancer Research, National Health and Medical Research Council (NHMRC) Career Development Fellowship 627015 (A.E.), and NHMRC Project grant 1050694 (A.E.).

Disclosures: None declared.
} 
Released by infiltrating neutrophils and eosinophils, respectively, these endogenous peroxidases have often been associated with fibrotic tissue in various organs without any direct involvement in fibroblast recruitment or extracellular matrix (ECM) biosynthesis attributed to their presence. For example, elevated accumulation of MPO is associated with augmented fibrosis seen in patients with atrial fibrillation, ${ }^{8}$ whereas EPO has been implicated in the pathogenesis of human endometriosis ${ }^{9}$ and experimental ulcerative colitis, ${ }^{10}$ where focally intense deposition of EPO localizes within fibrotic connective tissue. To date, the capacity of peroxidase proteins to induce a response involving fibroblastic recruitment and the synthesis and deposition of collagen-rich ECM has not been contemplated.

Herein, we report studies that characterize, for the first time, the ability of mammalian MPO and EPO as well as plantderived peroxidase proteins, such as horseradish peroxidase (HRP) and soybean peroxidase (SBP), to directly stimulate the migration and secretion of collagen I and collagen VI by fibroblasts in vitro and, ultimately, promote a fibrogenic response in vivo. We provide mechanistic data that show peroxidase enzymes regulate collagen I biosynthesis at a post-translational level that is $\mathrm{P} 4 \mathrm{H}$ dependent, but more important, does not require AA. Our studies demonstrate that the catalytic activity of MPO and EPO is essential to support collagen I biosynthesis by promoting $\mathrm{P} 4 \mathrm{H}-d e p e n d e n t$ hydroxylation and subsequent release of collagen from cells. Our novel findings that peroxidase enzymes, such as MPO and EPO, can substitute for AA to promote collagen biosynthesis strongly suggest that these enzymes play an important role not only in normal tissue repair, but also in the progression of disease states where infiltrating inflammatory cells are known to deposit peroxidases.

\section{Materials and Methods}

\section{Peroxidases}

Native human eosinophil peroxidase (EPO) was obtained from Cell Sciences (Canton, MA) and Lee Biosolutions Inc. (St. Louis, MO). HRP was purchased from Sigma-Aldrich (Sydney, NSW, Australia). Recombinant human MPO was purchased from R\&D Systems (Minneapolis, MN). SBP was obtained from Bio-Research Products, Inc. (North Liberty, IA).

\section{Fibroblast Cell Culture}

Primary human fibroblasts were grown in Dulbecco's modified Eagle's medium (DMEM; high glucose with no AA), supplemented with $2 \mathrm{mmol} / \mathrm{L}$ glutamine, $100 \mathrm{IU} / \mathrm{mL}$ penicillin, $100 \mu \mathrm{g} / \mathrm{mL}$ streptomycin, $20 \mathrm{mmol} / \mathrm{L} \mathrm{HEPES}$, and 10\% fetal bovine serum (FBS; Invitrogen Life Technologies, Carlsbad, CA) in a 5\% $\mathrm{CO}_{2}$-containing humidified atmosphere. Human foreskin fibroblasts (HFFs) were isolated and provided by Dr. Pritinder Kaur (Peter Mac Callum Institute, Melbourne, VIC, Australia) and used between cell passages 8 and 10. Adult dermal fibroblasts from two female donors were provided by Dr. John Greenwood (Royal Adelaide Hospital, Adelaide, SA, Australia) and used between passages 2 and 4. Human mammary gland-derived fibroblasts were provided by Dr. Wendy Ingman (The University of Adelaide, Adelaide, SA, Australia) and were isolated by enzymatic digestion of breast tissue, ${ }^{11}$ donated by five patients undergoing prophylactic mastectomies or cosmetic breast reduction surgery and used between passages 2 and 5 . Human prostate stromal fibroblasts ${ }^{12}$ were provided by Dr. Damien Leach (The University of Adelaide).

To evaluate the effect of peroxidases on collagen production, fibroblasts were seeded into 96-well plates at a density of $1.2 \times 10^{4}$ cells per well and cultured for 5 days in DMEM/10\% FBS until reaching confluence. Cells were starved overnight in serum-free DMEM and then stimulated for an additional 72 hours in serum-free DMEM containing either ascorbic acid 2-phosphate at $100 \mu \mathrm{mol} / \mathrm{L}$ (Wako Chemicals, Osaka, Japan) as a positive control or with the various peroxidase proteins in the absence of ascorbic acid supplementation. At the end of the 72-hour treatment period, fibroblast-conditioned media were collected for measurement of secreted, soluble type I and VI collagen by enzymelinked immunosorbent assay. Cell viability/growth was then assessed using the alamarBlue fluorescent dye assay (Invitrogen Life Technologies). Briefly, cells were incubated in a $10 \%$ alamarBlue/phosphate-buffered saline (PBS) solution for 30 minutes at $37^{\circ} \mathrm{C}$ and fluorescence measured at wavelengths of 530-nm excitation and 595-nm emission using a FLUOstar Optima plate reader (BMG Labtech Australia, Mornington, VIC, Australia). For time course studies, $6 \times 10^{4}$ HFFs were seeded into T25 culture flasks in DMEM/ $10 \%$ FBS and maintained in culture for 5 days. On reaching confluence, cells were starved in serum-free DMEM overnight and then stimulated with a maximal dose of $10 \mathrm{ng} / \mathrm{mL}$ transforming growth factor (TGF)- $\beta 2,100 \mu \mathrm{mol} / \mathrm{L}$ ascorbic acid 2-phosphate, $1 \mu \mathrm{g} / \mathrm{mL}$ SBP, or $1.56 \mu \mathrm{g} / \mathrm{mL}$ recombinant human MPO in serum-free DMEM. Cell-conditioned medium and total RNA were harvested at time points up to and including 72 hours. For Western blot analyses of collagen I in HFF-conditioned medium, $6 \times 10^{5}$ HFFs were seeded into T75 culture flasks in DMEM/10\% FBS and maintained in culture for 5 days. On reaching confluence, cells were starved in serum-free DMEM overnight and then stimulated in $8 \mathrm{~mL}$ serum-free DMEM containing either $100 \mu \mathrm{mol} / \mathrm{L}$ ascorbic acid 2-phosphate or $1.56 \mu \mathrm{g} / \mathrm{mL}$ peroxidases SBP, EPO, or MPO (for 72 hours).

\section{Collagen I and VI Enzyme-Linked Immunosorbent Assay}

The amount of soluble type I and VI collagen in cellconditioned medium was measured by a direct coat enzymelinked immunosorbent assay method using standard curves constructed from purified type I and VI human placental collagen (BD Biosciences Australia, North Ryde, NSW, 
Australia). Samples and standards (100 $\mu \mathrm{L}$ per well) were added to a 96-well Maxisorp plate (Nunc, Roskilde, Denmark) and left at $4^{\circ} \mathrm{C}$ overnight. The plate was then washed with PBS-Tween $0.05 \%, 2.5 \%$ bovine serum albumin (BSA)/PBS blocking solution was added to each well, and the plate was incubated for 1 hour at room temperature. The plate was then washed with PBS-Tween $0.05 \%$ and primary antibody $(0.25 \mu \mathrm{g} / \mathrm{mL}$ rabbit anti-human collagen I polyclonal; $0.25 \mu \mathrm{g} / \mathrm{mL}$ rabbit anti-human collagen VI polyclonal; Rockland Immunochemicals, Limerick, PA) in 5\% nonfat dairy milk added to each well for 3 hours at room temperature. After washing, europium-tagged anti-rabbit secondary antibody $(0.5 \mu \mathrm{g} / \mathrm{mL}$ in $1 \%$ BSA/PBS; Perkin Elmer Life Sciences, Turku, Finland) was added for 1 hour at room temperature. After a final wash, Enhancement Solution (Perkin Elmer Life Sciences) was added and fluorescence measured at excitation $355 \mathrm{~nm}$ and emission $620 \mathrm{~nm}$ using a FLUOstar Optima plate reader (BMG Labtech Australia). The collagen content of each sample was determined from the standard curve $(\mu \mathrm{g} / \mathrm{mL})$, then normalized to DMEM-only treated cells.

\section{Western Blot Analysis}

Culture medium from an equal number of HFFs grown in T75 flasks and stimulated for 72 hours in serum-free DMEM was resolved under reducing conditions in NuPAGE $4 \%$ to $12 \%$ Bis-Tris gels (Invitrogen Life Technologies) and electrophoretically transferred to Hybond-P polyvinylidene difluoride membranes (GE Healthcare Australia, Rydalmere, NSW, Australia) for 2 hours at $200 \mathrm{~mA}$. The filters were blocked with blocking buffer (5\% skim milk powder in Trisbuffered saline; $150 \mathrm{mmol} / \mathrm{L} \mathrm{NaCl}, 50 \mathrm{mmol} / \mathrm{L}$ Tris, and $0.2 \%$ Tween 20, $\mathrm{pH} 7.4$ ) overnight at $4{ }^{\circ} \mathrm{C}$ and then incubated for 1 hour with $0.5 \mu \mathrm{g} / \mathrm{mL}$ rabbit anti-human collagen I polyclonal (Rockland Immunochemicals). After extensive washing with several changes of Tris-buffered saline, the filters were incubated for 1 hour with alkaline phosphataseconjugated goat anti-rabbit IgG (Thermo Fisher Scientific, Scoresby, VIC, Australia) at a 1:5000 dilution in blocking buffer. After washing, immunoreactivity was detected by using the enhanced chemifluorescence substrate reagent kit (GE Healthcare Australia) on a FluorImager (GE Healthcare Australia). The thermal stability of collagen I released by HFFs into the culture medium was assessed by digestion with a mixture of trypsin and chymotrypsin (Sigma-Aldrich) for 2 minutes at the various temperatures indicated. ${ }^{13}$ After digestion, a $20-\mu \mathrm{L}$ aliquot was separated under reducing conditions in NuPAGE $4 \%$ to $12 \%$ Bis-Tris gels, and collagen I was analyzed by Western immunoblotting, as described above.

\section{Immunofluorescence Staining}

HFFs $\left(1.2 \times 10^{4}\right.$ cells per well $)$ were seeded onto circular glass coverslips in DMEM supplemented with $2 \mathrm{mmol} / \mathrm{L}$ glutamine, $100 \mathrm{IU} / \mathrm{mL}$ penicillin, $100 \mu \mathrm{g} / \mathrm{mL}$ streptomycin, $20 \mathrm{mmol} / \mathrm{L}$ HEPES, and 10\% FBS (Invitrogen Life Technologies) and maintained in culture overnight. Cells were then treated with either saline (Control) or $1 \mu \mathrm{g}$ of MPO or EPO in serum-free DMEM for up to 3 hours at $37^{\circ} \mathrm{C}$. After peroxidase exposure, indirect immunofluorescence staining was performed to detect cellular distribution of both MPO and EPO. In brief, cells were fixed with $4 \%$ formaldehyde with 5\% sucrose in PBS for 10 minutes. Cells were permeated with $0.25 \%$ Triton X-100 (Sigma-Aldrich) in PBS for 10 minutes to detect intracellular peroxidase uptake; non-specific binding sites were blocked by using 3\% BSA in PBS containing $0.1 \%$ glycine and a 1:10 dilution of nonimmune goat serum for $90 \mathrm{mi}-$ nutes. Cells were incubated for 1 hour with the primary antibodies $[1 \mu \mathrm{g} / \mathrm{mL}$ rabbit anti-human MPO from Dako Australia (North Sydney, NSW, Australia) (A0398); 1:1000 dilution of mouse anti-human EPO from Merck Millipore Australia (Bayswater, VIC, Australia) (MAB1087)] in PBS containing BSA at $1 \mathrm{mg} / \mathrm{mL}$ and then counterstained with a 1:1000 dilution of Alexa Fluor 488-conjugated goat antimouse or goat anti-rabbit IgG (Cell Signaling Technology, Beverly, MA) in PBS containing $1 \mathrm{mg} / \mathrm{mL}$ BSA. Coverslips were mounted onto glass slides using Fluoromount (SigmaAldrich), and images were captured using a fluorescence photomicroscope (Observer Z1; Carl Zeiss Microscopy, Jena, Germany).

\section{RNA Isolation and Quantitative Real-Time PCR}

To evaluate the effect of peroxidases on collagen type I $\alpha$ mRNA expression by HFFs, total RNA was isolated using an RNeasy Mini Kit (Qiagen Australia, Chadstone, VIC, Australia) according to the manufacturer's instructions. RNA yield and purity were quantified by Nanodrop spectrophotometric measurement at $260 \mathrm{~nm}$ (Thermo Fisher Scientific, Scoresby, VIC, Australia). Collagen I $\alpha$ mRNA expression was examined using real-time RT-PCR and normalized against glyceraldehyde-3phosphate dehydrogenase. cDNA was synthesized by reverse transcription of $1 \mu \mathrm{g}$ total RNA using random hexamer primers and SuperScript III Reverse Transcriptase (Invitrogen Life Technologies). Real-time RT-PCR was performed using SYBR Green Fluor qPCR mastermix (Qiagen Australia) in a CFX96 Real-Time System (BioRad, Hercules, CA). Each reaction volume of $25 \mu \mathrm{L}$ contained cDNA templates, primer pairs, and SYBR Green mastermix. Amplification occurred after initial denaturation at $95^{\circ} \mathrm{C}$ for 3 minutes, followed by 40 cycles at $95^{\circ} \mathrm{C}$ for 15 seconds, $60^{\circ} \mathrm{C}$ for 26 seconds, and $72^{\circ} \mathrm{C}$ for 10 seconds. The primer combination used for collagen I $\alpha 1$ was as follows: $5^{\prime}$-AGGGCTCCAACGAGATCGAGATCCG-3' (forward) and 5'-TACAGGAAGCAGACAGGGCCAACGTCG-3' (reverse). Expression values were normalized to the housekeeping gene glyceraldehyde-3-phosphate dehydrogenase using the following primer combination: $5^{\prime}$-ACCCAGAAGACTGTGGATGG-3' (forward) and 5'-TCAGTGAGCTTCCCGTTCAG-3' (reverse). 


\section{Cell Migration Assay}

HFF migration was determined using the 24-well FluoroBlok transwell plate (BD Biosciences Australia) system with 8.0$\mu \mathrm{m}$ pore positron emission tomography membranes. Briefly, HFFs were then seeded in serum-free DMEM at 10,000 cells per well into the upper wells. Cells were then incubated at $37^{\circ} \mathrm{C}$ for 30 minutes to allow cell adhesion. Lower chambers were then filled with $700 \mu \mathrm{L}$ of serum-free DMEM as the vehicle control, DMEM containing $1 \mathrm{ng} / \mathrm{mL}$ TGF- $\beta 2$ serving as the positive control, or DMEM with the various peroxidase proteins (MPO, EPO, and SBP) at $2 \mu \mathrm{g} / \mathrm{mL}$. After 20-hour incubation at $37^{\circ} \mathrm{C}$, the inserts were gently taken out and the upper side of the membrane scraped using a cotton swab to remove cells that had attached but not migrated. Cells that had migrated to the underside of the transwell membrane were fixed in 6:1 ethanol/acetic acid for 10 minutes and stained with DAPI $(1 \mu \mathrm{g} / \mathrm{mL})$, then imaged and quantified on a fluorescent inverted microscope (Carl Zeiss Microscopy).

\section{INTEGRA Studies}

INTEGRA Dermal Regeneration Template (INTEGRA LifeSciences, Plainsboro, NJ) was cut into $1 \times 1-\mathrm{cm}$ pieces and washed with PBS, followed by serum-free DMEM to remove the alcohol storage medium and to equilibrate the porous scaffold for exposure to cells. The INTEGRA pieces were then transferred to a 24-well tissue culture plate (collagen layer facing up) and immersed in DMEM, with or without peroxidase, for up to 2 hours at $37^{\circ} \mathrm{C}$ in a $\mathrm{CO}_{2}$ incubator. After the preincubation binding period, the media were replaced with fresh DMEM supplemented with 5\% human serum containing $5 \times 10^{5}$ human fibroblast cells, with or without SBP or HRP at $25 \mu \mathrm{g} / \mathrm{mL}$. The INTEGRA pieces were incubated for up to 14 days, with the media changed after 7 days. At the end of the experiment, the INTEGRA pieces were imaged, harvested, and fixed in 10\% buffered formaldehyde, processed, embedded in paraffin wax, and divided into sections for histological and immunohistochemical analysis.

For immunohistochemistry, sections ( $6 \mu \mathrm{m}$ thick) of the INTEGRA were mounted on silane-coated slides, dewaxed, and hydrated before placing into an endogenous peroxidase blocking solution for 30 minutes $\left(0.5 \% \mathrm{H}_{2} \mathrm{O}_{2} /\right.$ methanol). After washing in PBS, sections were incubated in $3 \%$ normal horse serum blocking solution for 30 minutes and then primary antibody overnight $[2.5 \mu \mathrm{g} / \mathrm{mL}$ rabbit anti-smooth muscle actin (AbCam, Melbourne, VIC, Australia); $5 \mu \mathrm{g} / \mathrm{mL}$ rabbit anti-collagen I and collagen VI (Rocklands Immunochemicals)]. The sections were then washed in PBS and incubated with $6 \mu \mathrm{g} / \mathrm{mL}$ anti-rabbit IgG biotin. After a further PBS wash, $2 \mu \mathrm{g} / \mathrm{mL}$ streptavidin HRP tertiary antibody was applied for 1 hour, followed by the addition of 3,3'-diaminobenzidine peroxidase substrate solution (Sigma-Aldrich) to the sections until brown color development was visible. The sections were then washed thoroughly in PBS and water before counterstaining with hematoxylin, dehydrating, and mounting with
DPX Mountant (Sigma-Aldrich). Sections were also stained with DAPI (Pierce Biotechnology, Rockford, IL) to visualize cells within the INTEGRA template under fluorescent microscopy. DAPI was used at a final concentration of $1 \mu \mathrm{g} / \mathrm{mL}$, following the manufacturer's instructions, and cell counts were performed using the VisionWorks LS Aquisition and Analysis program (UPC Ltd, Cambridge, UK). Images were captured using a Nikon Eclipse 50i microscope attached to a DS-L2 control unit (Digital Sight; Nikon Europe, Amsterdam, the Netherlands) and a DS-Fil digital camera (Nikon Corporation, Tokyo, Japan).

\section{In Vivo Rat Studies}

Female Sprague-Dawley rats $(n=4)$ were lightly anesthetized, and the dorsum was shaved. At different sites on their dorsum, each rat received a bolus intradermal injection of four doses of peroxidase protein (SBP, 1.25 to $25 \mu \mathrm{g}$ ) or the vehicle control, which was $0.9 \%$ saline. Agents were injected in a volume of 50 $\mu \mathrm{L}$, which was sufficient to generate a small blister in the skin that resolved within a few minutes. Across the group of rats, each dose was injected into a different injection site to control for any site-related, intrarat variation. After 3 days, the rats were sacrificed by $\mathrm{CO}_{2}$ asphyxiation and the skin at the injection sites was excised using a 6-mm biopsy punch, with each piece bisected and fixed in $10 \%$ buffered formalin.

Fixed tissue was processed for histological assessment by graded dehydration and mounting in paraffin blocks. Sections (6 $\mu \mathrm{m}$ thick) were stained with hematoxylin and eosin (H\&E) and Masson's trichrome for qualitative analysis by an experienced pathologist. H\&E-stained sections were scored for the fibroblast reaction $(1+$ to $3+)$ to reflect the number of fibroblast cells identified at the injection site, with $3+$ representing the greatest response. H\&E- and Masson's trichrome-stained sections were used to evaluate the amount of deposited, collagen-rich ECM that was associated with the fibroblast reaction at each injection site. The ECM deposition was scored $1+$ to $3+$, with $3+$ representing the greatest response. The scores were combined across the group of rats, and statistical analysis was performed using a Kruskal-Wallis one-way analysis of variance on ranks, followed by a post hoc $t$-test comparing the response of the proteins with peroxidase activity to the control using Dunnett's method. $P<0.05$ was considered significant.

All in vivo studies were approved by the Animal Ethics Committee of the Institute for Medical and Veterinary Sciences (Adelaide, SA, Australia), and performed in accordance with the National Health and Medical Research Council of Australia code of practice for the care and use of animals for scientific purposes.

\section{In Vivo Porcine Studies}

To determine the ability of peroxidase proteins to promote tissue regeneration in vivo, a study was performed in pigs (large white/Landrace cross sows) where INTEGRA 
A

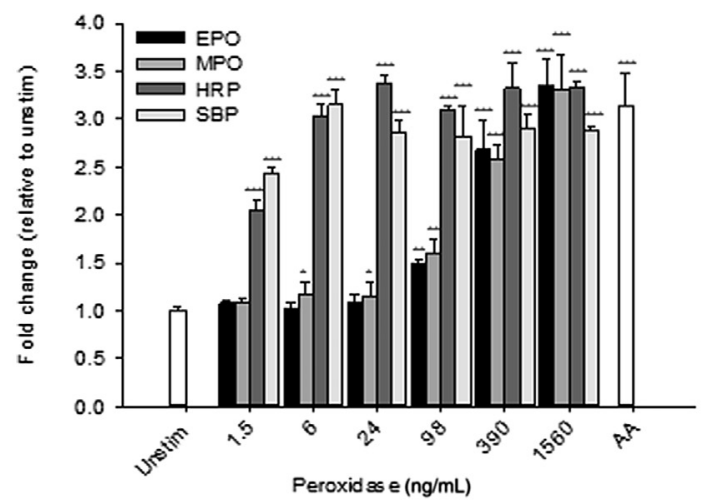

C

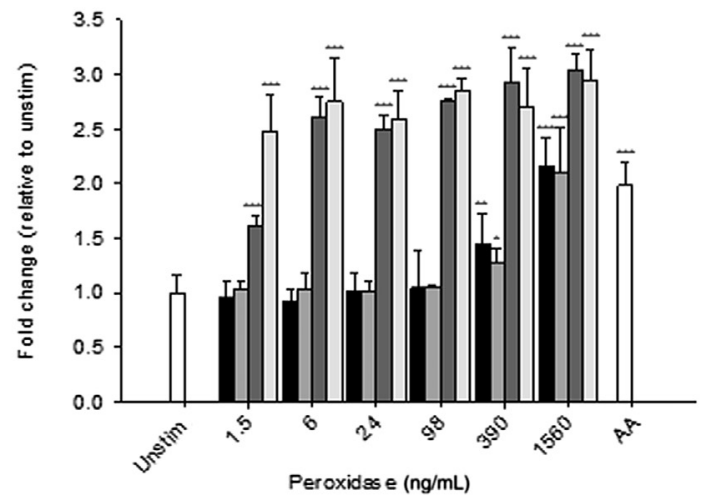

B

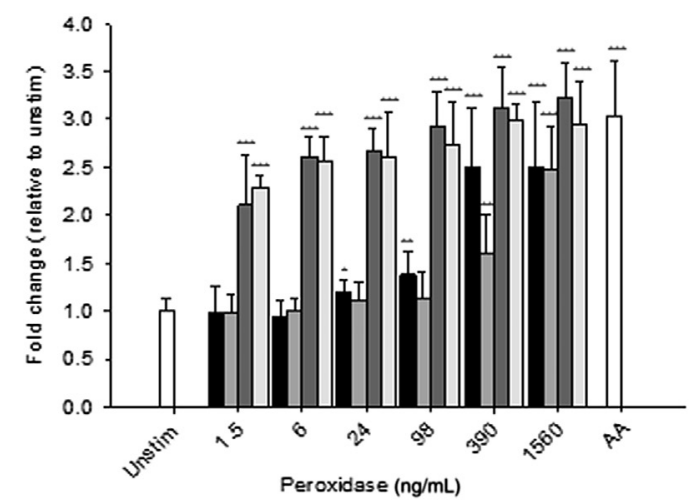

Collagen VI - Adult dermal fibroblasts

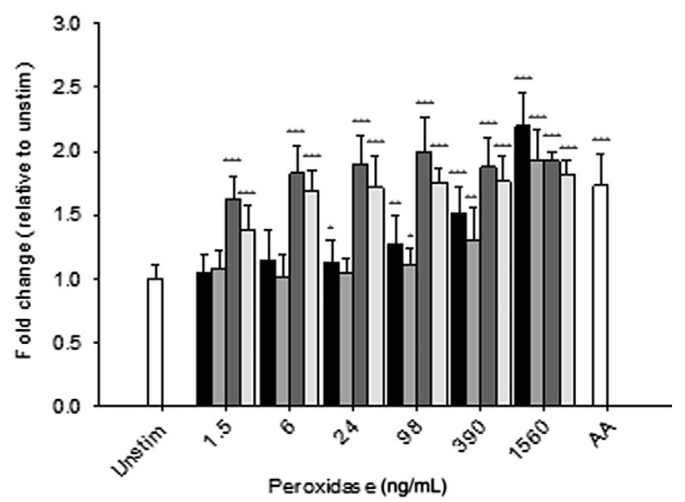

Figure 1 Mammalian and plant-derived peroxidase enzymes promote collagen I and VI release by human dermal fibroblasts. Enzyme-linked immunosorbent assay detection of soluble collagen I ( $\mathbf{A}$ and $\mathbf{B}$ ) and collagen VI (C and $\mathbf{D})$ in human foreskin fibroblasts (HFFs) and adult dermal fibroblast-conditioned medium after 72 hours of stimulation with peroxidases at the doses indicated. Ascorbic acid 2-phosphate (AA) at $100 \mu \mathrm{mol} / \mathrm{L}$ served as the positive control, whereas the cells treated with Dulbecco's modified Eagle's medium (DMEM) alone (unstim) served as the baseline control. The levels of collagen I and VI are expressed as fold change, normalized so the average values of unstim were set to 1 . Statistical significance was calculated by two-tailed Student's $t$-test with the various treatment groups compared to the DMEM alone (unstim) group. Data for adult dermal fibroblasts are pooled from experiments conducted using cells derived from two individual donors. Dose-response experiments using HFFs were independently performed at least 10 times, whereas studies using adult fibroblasts were repeated three times. Data are the means \pm SD of triplicate determinations for unstim, AA, and each peroxidase dose. ${ }^{*} P<0.05$, ${ }^{* *} P<0.01$, and ${ }^{* * *} P<0.001$. EPO, eosinophil peroxidase; HRP, horseradish peroxidase; MP0, myeloperoxidase; SBP, soybean peroxidase.

$( \pm 100 \mu \mathrm{g} / \mathrm{mL} \mathrm{SBP})$ was grafted onto full-thickness excisional wounds, as previously described. ${ }^{14}$

Two female domestic large white $\times$ Landrace pigs, weighing between 15 and $20 \mathrm{~kg}$, obtained from The University of Adelaide Minimal Disease Piggery were used for this study. After induction of anesthesia by gaseous isoflurane, animals were intubated and deep anesthesia was maintained throughout the surgical intervention. The skin on the dorsum of the animal was rigorously prepared before generating four $3 \times 3-\mathrm{cm}$ square full-thickness wounds at two positions equidistant from the midline on either side. The site preparation involved removing the hair by clipping and application of a depilatory cream (Nair; Church and Dwight Australia, Frenchs Forest, NSW, Australia), followed by repeated scrubbing with MediSponges containing povidone-iodine (Betadine; Sanofi Australia, Macquarie Park, NSW, Australia). The margins of the wounds were infiltrated with $0.25 \%$ bupivacaine (Marcaine;
AstraZeneca Australia, North Ryde, NSW, Australia) containing 1:400,000 adrenaline to facilitate hemostasis and afford postoperative analgesia. The skin was excised to the fascia layer and hemostasis effected by diathermy. INTEGRA pieces that had been soaked in a solution containing $100 \mu \mathrm{g} / \mathrm{mL}$ SBP or a saline solution (control) for 3 hours were placed into the wounds and secured in place with steel staples. The wounds were then covered by a moistened Acticoat dressing (Smith \& Nephew, Hull, UK), which was secured in place using Hypafix. The whole site was then protected using combine dressings underneath crepe bandages and an elasticized abdominal binder.

The animals were dosed postoperatively with s.c. $250 \mathrm{mg}$ enrofloxacin (Baytril 50; Bayer Australia, Pymble, NSW, Australia) as a prophylactic antibiotic. On day 7, the animals were anesthetized and paired 6-mm punch biopsy specimens were collected from control and SBP-treated INTEGRA wounds. The biopsy specimens were fixed in $10 \%$ formalin, 
processed, and embedded in paraffin, and sections were stained with H\&E and Masson's trichrome for histological assessment. Images were captured using a Nikon Eclipse 50i microscope attached to a DS-L2 control unit (Digital Sight) and a DS-Fil digital camera (Nikon Corporation).

\section{Results}

\section{Peroxidases Stimulate Fibroblasts in Vitro to Secrete Collagens Type I and VI}

Type I collagen is the most abundant collagen found in the body, where it plays an important role in maintaining the structural integrity of the major organs, including skin. When stimulated with MPO or EPO in the absence of AA, HFFs demonstrated a dose responsiveness to both mammalian peroxidases. Like AA, which was used as a control, maximal stimulation with the peroxidases increased the amount of collagen I released into the medium approximately threefold (Figure 1A). To establish whether induction of collagen I secretion was restricted only to mammalian peroxidases, we also tested peroxidase enzymes purified from plant sources. Both SBP and HRP were potent stimulators of collagen biosynthesis, achieving a maximal threefold increase in collagen I release by HFFs, but at substantially lower doses (Figure 1A).

Collagen VI is another form of collagen that plays an important structural role in maintaining skin integrity, with a recent report showing skin of Col6 $\alpha 1$-null mice has decreased tensile strength and abnormal collagen I fibril architecture. ${ }^{15}$ Examination of soluble collagen VI synthesis by HFFs revealed a similar release profile to that seen for collagen I, with all peroxidases tested inducing a response that was equal to, or greater than, that seen with AA stimulation (Figure 1B). Throughout these experiments, the peroxidase proteins had no impact on the proliferation or viability of the confluent fibroblasts (data not shown).

To ensure the response to the peroxidase proteins was not specific to neonatal fibroblasts, we tested the range of peroxidase enzymes on fibroblasts derived from skin removed during abdominoplasty from adult female donors. Consistent with our observations made using HFFs, the combined data from two adult donors showed that all four peroxidases tested induced significant increases in collagen I and VI secretion in the absence of AA (Figure 1, C and D). Although the plantderived peroxidases were again most potent, both EPO and MPO stimulated levels of collagen I and VI release that were comparable to the effect observed with AA alone. Peroxidases showed no significant impact on the viability or number of adult dermal fibroblasts (data not shown).

The ability of peroxidase enzymes to stimulate collagen I release in the absence of AA does not appear to be restricted solely to fibroblasts sourced from dermal tissue. Combined data from five donors show that cultured mammary fibroblasts also respond to both EPO and MPO and induce a significant increase in collagen I secretion (Figure 2A). Similarly, a twofold increase in collagen I release was observed when

\section{A \\ Collagen I-Mammary fibroblasts}

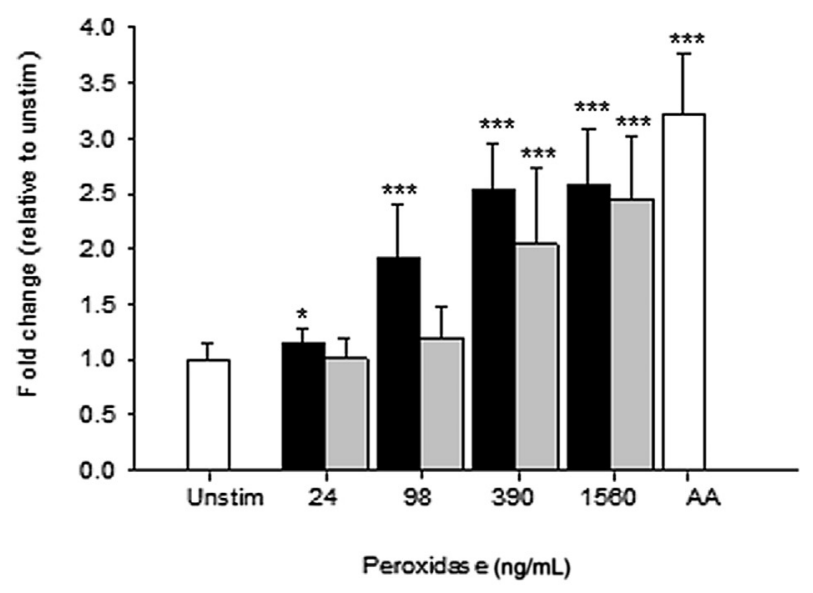

B

Collagen I - Prostate fibroblasts

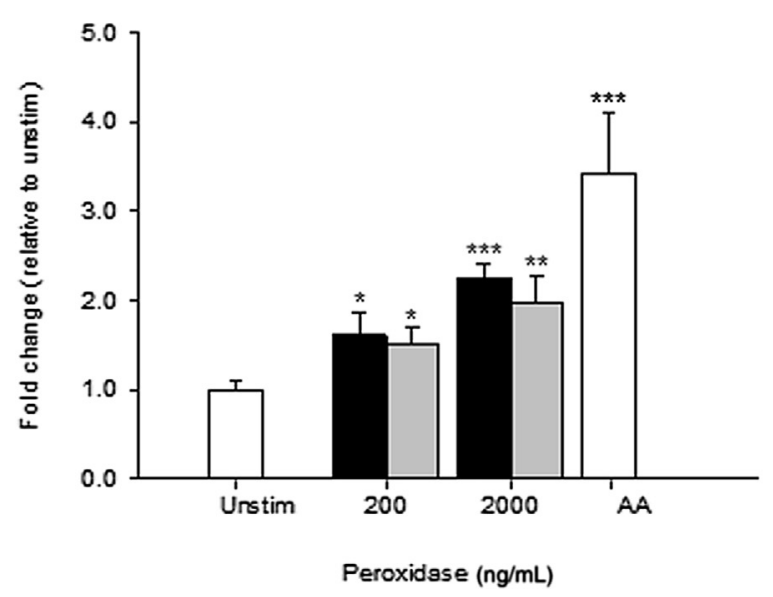

Figure 2 Eosinophil peroxidase (EPO; black bars) and myeloperoxidase (MPO; gray bars) promote collagen I release by human mammary- and prostate-derived fibroblasts. Enzyme-linked immunosorbent assay detection of soluble collagen I in primary human mammary fibroblast- $(\mathbf{A})$ and human prostate cancer-associated fibroblast- (B) conditioned medium after 72 hours of stimulation with EPO and MPO at the doses indicated. Ascorbic acid 2-phosphate (AA) at $100 \mu \mathrm{mol} / \mathrm{L}$ served as the positive control, whereas cells treated with Dulbecco's modified Eagle's medium (DMEM) alone (unstim) served as the baseline control. The levels of collagen I are expressed as fold change, normalized so the average values of unstim were set to 1 . Statistical significance was calculated by two-tailed Student's $t$-test with the various treatment groups compared to the DMEM alone (unstim) group. Data for mammary fibroblasts are pooled from experiments conducted using cells derived from five individual donors. Data for the prostate cancer-associated fibroblasts are pooled from two separate experiments. Data are the means $\pm S D$ of triplicate determinations for unstim, $A A$, and each peroxidase dose. ${ }^{*} P<0.05,{ }^{*} P<0.01$, and ${ }^{* * *} P<0.001$.

cultured human prostate fibroblasts were stimulated with EPO or MPO in the absence of AA (Figure 2B).

\section{Peroxidases Promote Fibroblast Migration in Vitro}

Fibroblast migration is central to many normal and pathological processes involving tissue remodeling, where new 


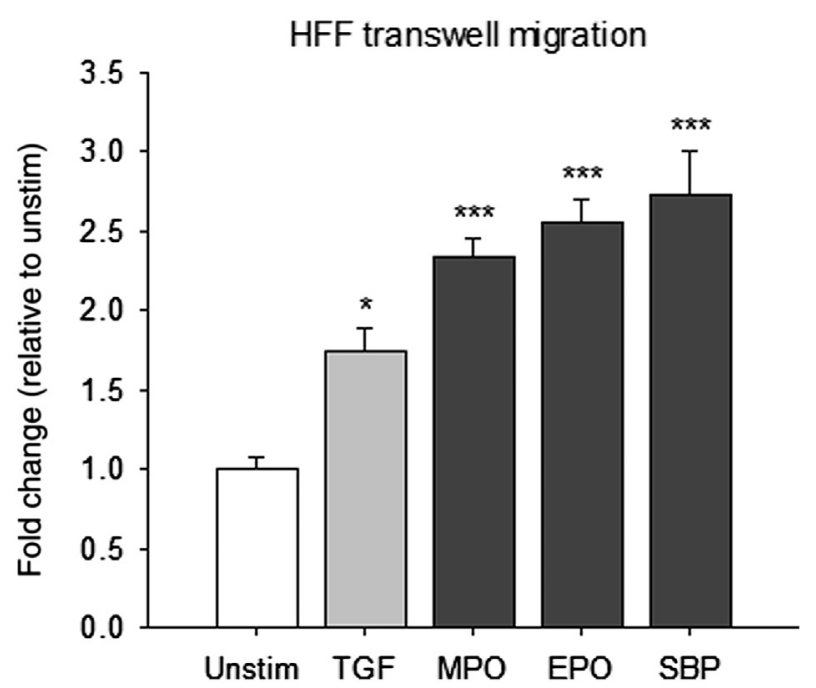

Figure 3 Peroxidase enzymes promote fibroblast migration in vitro. Migration of human foreskin fibroblasts (HFFs) across transwell membranes after 20 hours of exposure to the peroxidase enzymes eosinophil peroxidase (EP0), myeloperoxidase (MPO), or soybean peroxidase (SBP) at $2 \mu \mathrm{g} / \mathrm{mL}$ in the lower chamber. Transforming growth factor (TGF)- $\beta 2$ at $1 \mathrm{ng} / \mathrm{mL}$ in the lower chamber served as the positive control, whereas cells treated with Dulbecco's modified Eagle's medium (DMEM) alone (unstim) in both chambers served as the baseline control. The level of cell migration is expressed as fold change, normalized so the average values of unstim were set to 1. Statistical significance was calculated by two-tailed Student's $t$-test with the various treatment groups compared to the DMEM alone (unstim) group. Data are the means $\pm S D$ of triplicate determinations for unstim, TGF- $\beta 2$, and each peroxidase. ${ }^{*} P<0.05,{ }^{* * *} P<0.001$.

collagen-rich ECM is deposited, including wound repair, fibrosis, cancer growth, and metastasis. To establish whether peroxidase enzymes could provide a chemotactic stimulus to promote fibroblast migration in vitro, a transwell system was used where HFFs were seeded in the upper chamber with peroxidases present in the lower chamber acting as chemoattractants. During a 20-hour period, cell counts show the peroxidase enzymes MPO, EPO, and SBP significantly increased HFF migration approximately 2.5 -fold compared to the control (unstimulated), a response slightly greater to that achieved with the positive control TGF- $\beta 2$ (Figure 3).

\section{Peroxidases Stimulate a Fibrogenic Response When Injected in Vivo}

To confirm that peroxidase proteins could induce the same effects in vivo as those seen in vitro, SBP was injected intradermally into the skin of female rats. The results shown were obtained 72 hours after SBP was injected (Figure 4, A-D). Compared to normal dermis (Figure 4A), the area injected with peroxidase protein showed a marked increase in cellularity and newly formed ECM (Figure 4C), which was confirmed by staining serial sections with Masson's trichrome (data not shown). Although there was some lymphocytic cell involvement in the response to SBP, the cells were predominantly fibroblasts, as demonstrated by the strong positive staining for smooth muscle actin (Figure 4D). The blinded, histological evaluation of the injection sites from four rats injected with SBP showed that the peroxidase protein induced a dose-dependent fibrogenic response comprising an overall fibroblastic reaction (ie, increased fibroblast accumulation) and increased ECM deposition (Figure 4E). No apparent increase in the number of fibroblast mitotic bodies was evident, as confirmed by an absence of positive staining when the sections were incubated with an antibody against proliferating cell nuclear staining (data not shown). This accumulation of smooth muscle actin-positive cells appears to be due predominantly to the infiltration of fibroblasts into the site of SBP injection, rather than increased proliferation of resident cells. In addition, the response was no longer evident after 7 days,
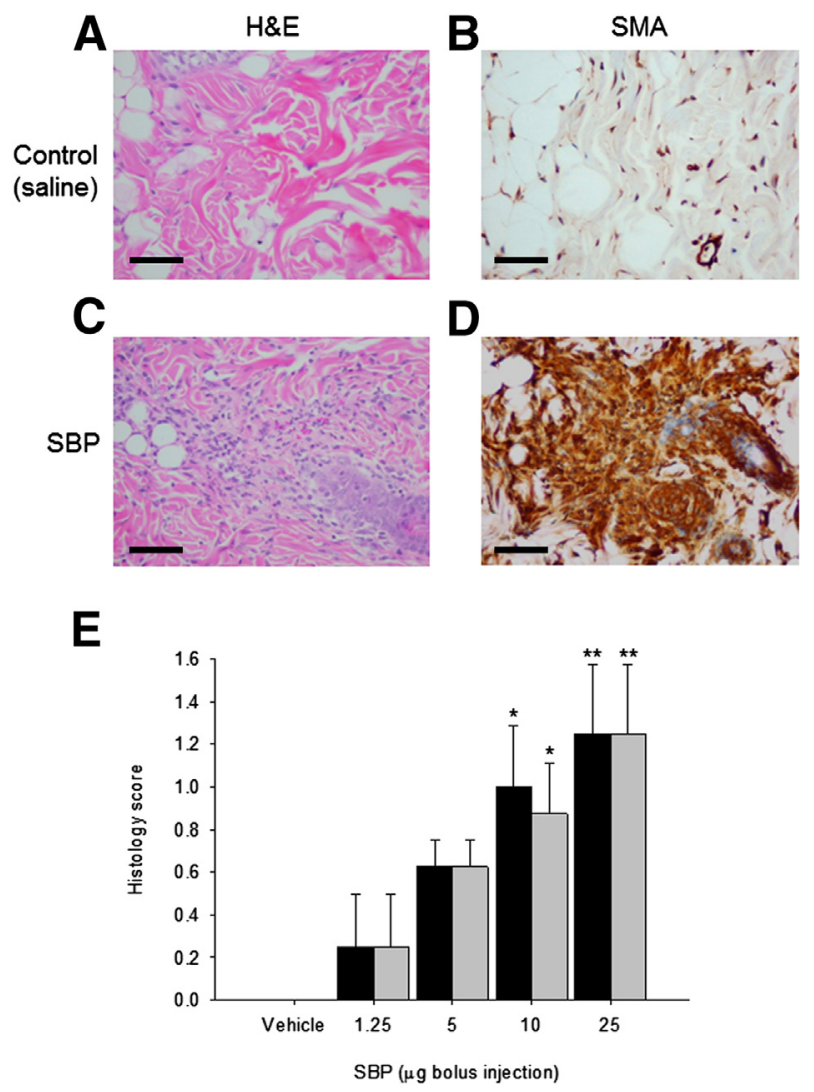

Figure 4 Peroxidases stimulate fibroblast migration and extracellular matrix (ECM) production in rats when injected intradermally. A and C: Representative images of hematoxylin and eosin (H\&E)-stained sections taken 3 days after rats were injected intradermally with either saline (control) or a $25-\mu \mathrm{g}$ bolus dose of soybean peroxidase (SBP). B and D: Representative images of smooth muscle actin (SMA) immunostaining showing fibroblast distribution in tissue sections 3 days after intradermal injection with either saline (control) or a $25-\mu \mathrm{g}$ bolus dose of SBP. E: Histological evaluation of H\&E- and Masson's trichrome-stained sections measuring overall tissue fibroblast reaction (black bars) and extracellular matrix (ECM) deposition (gray bars) 3 days after various doses of SBP were injected intraderamlly into rats. Statistical significance was calculated using a Kruskal-Wallis one-way analysis of variance on ranks, followed by a post hoc $t$-test comparing the response of the proteins with peroxidase activity to the control (vehicle) using Dunnett's method. The intradermal injection of peroxidase enzymes into rats was independently performed three times. Data are the means $\pm \operatorname{SEM}(\mathrm{E}) . n=4$ rats per group $(\mathrm{E})$. ${ }^{*} P<0.05,{ }^{* *} P<0.01$. Scale bar $=250 \mu \mathrm{m}$ (A-D). 
A

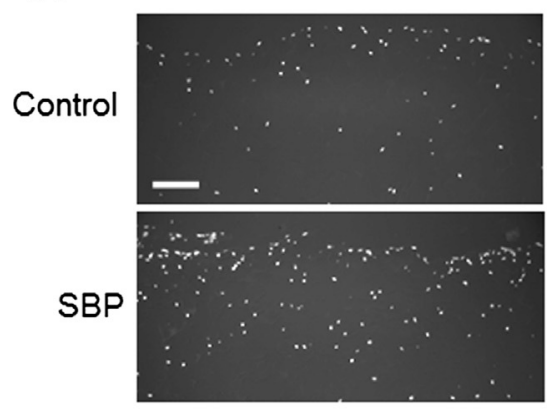

C

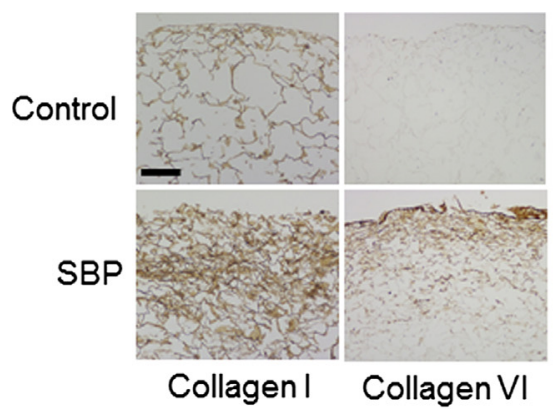

B

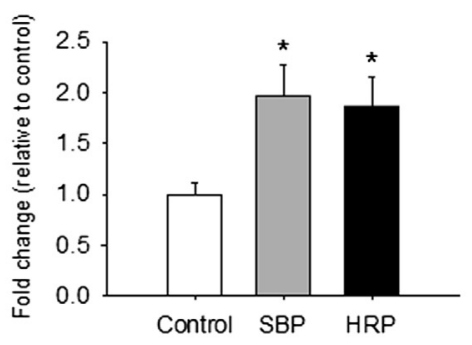

D

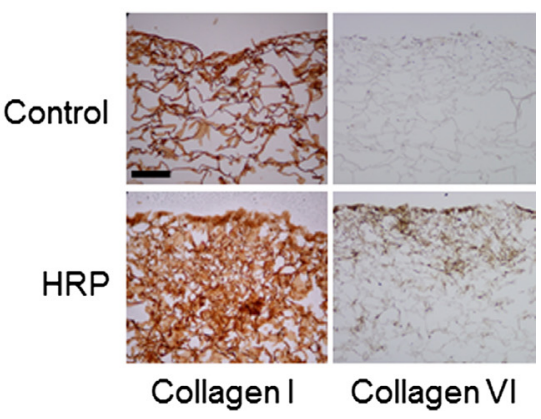

Figure 5 Peroxidases promote fibroblast migration and collagen extracellular matrix (ECM) deposition in vitro. A: Representative images of DAPI-stained INTEGRA dermal regeneration template showing adult dermal fibroblast localization after 7 days of culture without peroxidase (control) or stimulated with soybean peroxidase at $25 \mu \mathrm{g} / \mathrm{mL}$ (SBP). B: Cell counts of DAPI-stained adult dermal fibroblasts within INTEGRA sections after 7 days of culture without peroxidase (control), stimulated with soybean peroxidase at 25 $\mu \mathrm{g} / \mathrm{mL}$ (SBP) or horseradish peroxidase at $25 \mu \mathrm{g} / \mathrm{mL}$ (HRP). Pooled data from five experiments. Statistical significance was calculated by two-tailed Student's $t$ test. C: Representative images of INTEGRA harvested after 14 days of culture with adult dermal fibroblasts maintained without peroxidase (control) or stimulated with soybean peroxidase at $25 \mu \mathrm{g} / \mathrm{mL}$ (SBP) showing both collagen I and collagen VI distribution by immunostaining. D: Representative images of INTEGRA harvested after 14 days of culture with adult dermal fibroblasts maintained without peroxidase (control) or stimulated with horseradish peroxidase at $25 \mu \mathrm{g} / \mathrm{mL}$ (HRP) showing both collagen I and collagen VI distribution by immunostaining. Each in vitro experiment using INTEGRA was independently performed at least five times. Data are the means $\pm \operatorname{SEM}(\mathbf{B}) .{ }^{*} P<0.05$ compared to control (B). Scale bars: $400 \mu \mathrm{m}$ (A); 250 $\mu \mathrm{m}$ (C and D). indicating remodeling had occurred, as would be expected of an acute-phase, fibroblastic response without the involvement of a chronic, inflammatory component.

\section{Peroxidases Promote Tissue-Like Regeneration in Vitro}

We next sought to determine whether stimulation of fibroblasts with peroxidase enzymes could result in the generation of cell-associated collagen-rich ECM. For these studies, we used INTEGRA Dermal Regeneration Template as a premade three-dimensional collagen/glycosaminoglycan scaffold that was seeded with adult donor fibroblasts. The plant peroxidases SBP and HRP were chosen for these studies, because these enzymes stimulate the most potent collagen response of all peroxidases tested in adult fibroblast monolayer cultures (Figure 1, C and D). After 7 days, we noted a consistent difference in the ability of cells to infiltrate into INTEGRA when treated with peroxidases compared to culture medium alone. This was illustrated by DAPI staining, where INTEGRA slices treated with SBP showed elevated numbers of fibroblasts extending throughout the scaffold, indicating that the cells had either attached themselves to the collagen fibers of the scaffold or migrated into the interstices between the fibers (Figure 5A). In comparison, media alone were not effective at promoting cell migration into the INTEGRA (Figure 5A). Cell counts compiled from DAPI-stained sections demonstrated that both SBP and HRP effectively doubled the number of cells populating the INTEGRA after 7 days (Figure 5B).

The ability of cells that had migrated into the INTEGRA scaffold to deposit a collagen-rich ECM in response to the treatment with peroxidase proteins was assessed by immunostaining for collagen I using a polyclonal antibody that also cross-reacts with bovine collagen I. As a result, the fibers making up the INTEGRA stained positive in all images shown for collagen I staining (Figure 5, C and D). Cell/ INTEGRA composites, generated using cells from adult donors and cultured without peroxidase protein for 2 weeks, showed predominantly this endogenous staining pattern with minimal cell-associated collagen I-positive staining evident (Figure 5, C and D). In contrast, when SBP or HRP was included in the media, collagen I staining was observed throughout the interstices of the INTEGRA, clearly indicating the peroxidase proteins stimulated the robust deposition of collagen I-enriched ECM (Figure 5, C and D).

The collagen VI antibody did not cross-react with the collagen I component of the INTEGRA scaffold, and minimal collagen VI was deposited within the interstices of the scaffold when the cell/INTEGRA composite was cultured without peroxidase proteins (Figure 5, C and D). Conversely, when SBP or HRP was included in the media, profuse deposition of collagen VI was observed throughout the matrix (Figure 5, C and D).

\section{Peroxidases Induce Connective Tissue Regeneration in Vivo}

To determine whether an in vivo fibrogenic response could be elucidated within the INTEGRA scaffold by the peroxidase proteins, INTEGRA presoaked with normal saline (control) or with SBP for 3 hours was grafted onto full-thickness dermal wounds on the dorsum of pigs (Figure 6, A and B). 

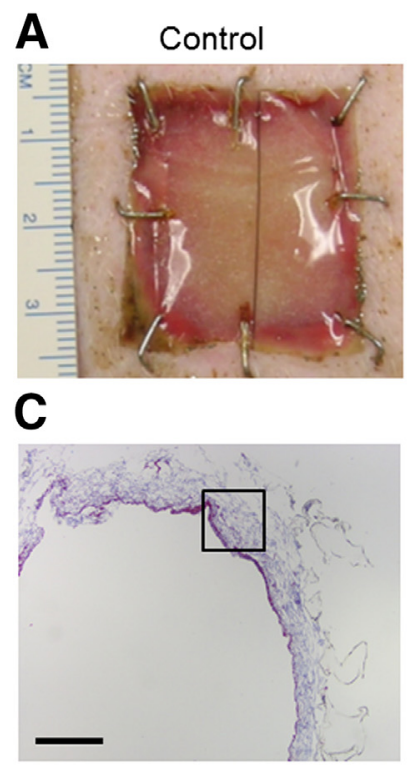

E
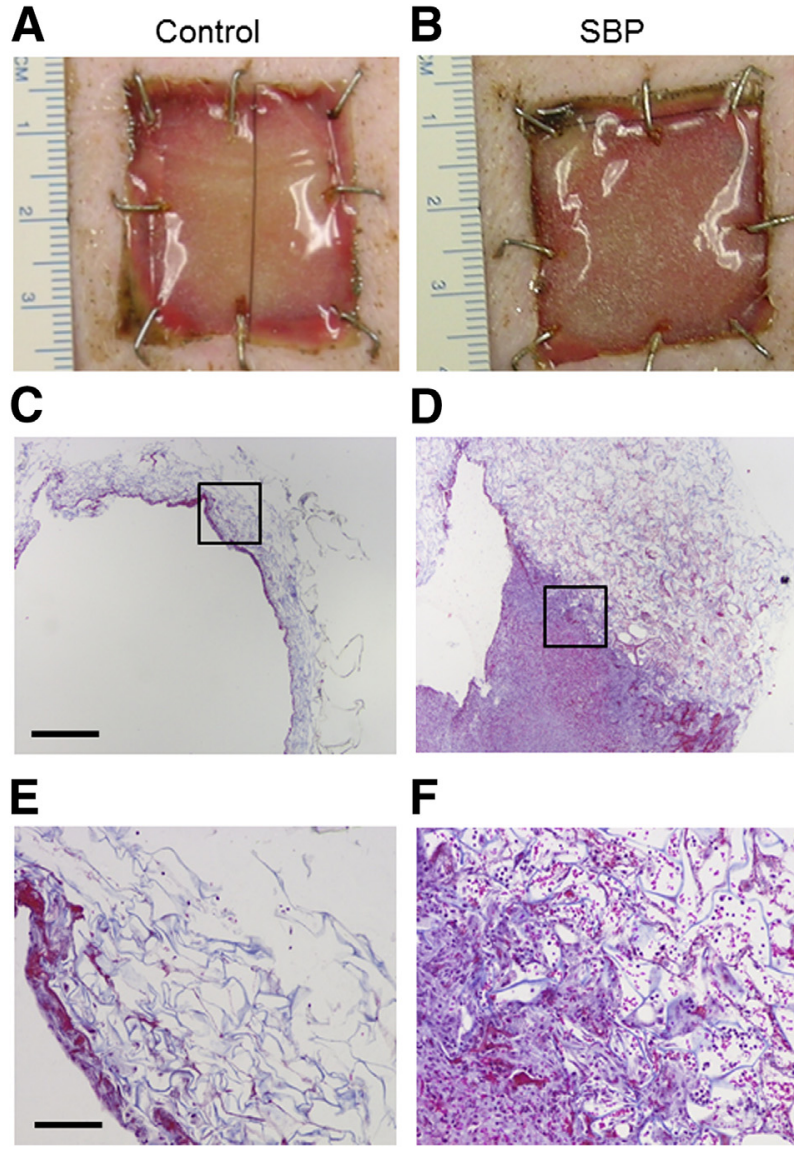

D

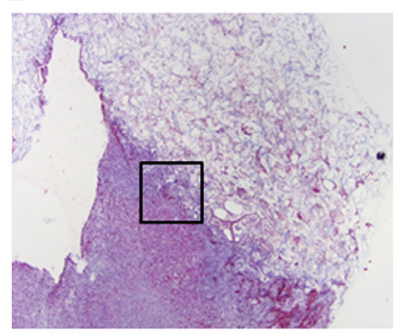

$\mathbf{F}$

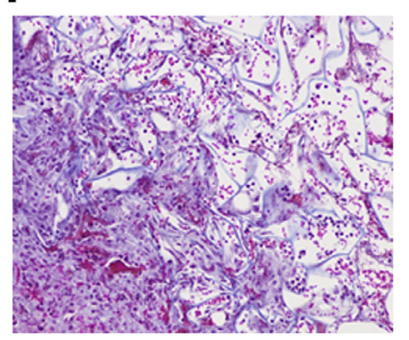

Figure 6 Peroxidase enzymes stimulate potent tissue regeneration in vivo when combined with INTEGRA dermal regeneration template. A and B: The wounds with INTEGRA stapled in place (control and SBP treated, respectively) before biopsy collection at 7 days after surgery. $\mathbf{C}$ and $\mathbf{D}$ : Representative lowpower images of sections stained with Masson's trichrome, clearly showing that only the INTEGRA itself is harvested from the control wound (C), whereas INTEGRA and the underlying wound tissue are recovered from the SBP wound (D). E and F: Representative higher-magnification images of boxed areas in panels $\mathbf{C}$ and $\mathbf{D}$ showing the control INTEGRA is poorly infiltrated with cells from the wound bed $(\mathbf{E})$, whereas the INTEGRA treated with SBP $(\mathbf{F})$ shows numerous fibroblasts and inflammatory cells interspersed with new extracellular matrix deposited between the INTEGRA fibers at the wound bed interface. The pig excisional wound model using INTEGRA was independently performed on two pigs with similar results. Scale bars: $600 \mu \mathrm{m}$ (C and D); $120 \mu \mathrm{m}$ (E and F). Original magnifications: $\times 40(\mathbf{C}$ and D); $\times 200(\mathbf{E}$ and F).

Histological analysis of biopsy specimens collected 7 days after the INTEGRA grafting showed strong evidence of advanced integration of the peroxidase-treated INTEGRA with the underlying wound bed (Figure 6D). Closer inspection shows that the control INTEGRA was poorly infiltrated with cells from the wound bed (Figure 6, C and E), resulting in poor attachment and the separation of the INTEGRA from the wound tissue during collection. In contrast, the INTEGRA treated with SBP was well integrated with new granulation tissue from the wound (Figure 6F), showing numerous fibroblasts and new collagen-rich ECM interspersed between the fibers of the INTEGRA at the interface with the wound bed, along with several inflammatory cells.

\section{Peroxidases Regulate P4H-Dependent Post-Translational Collagen I Biosynthesis}

To investigate the mechanism by which peroxidase enzymes regulate collagen I biosynthesis, we compared the effect of MPO and SBP to the time-dependent secretion of collagen I stimulated by either AA or TGF- $\beta 2$. In the absence of AA,

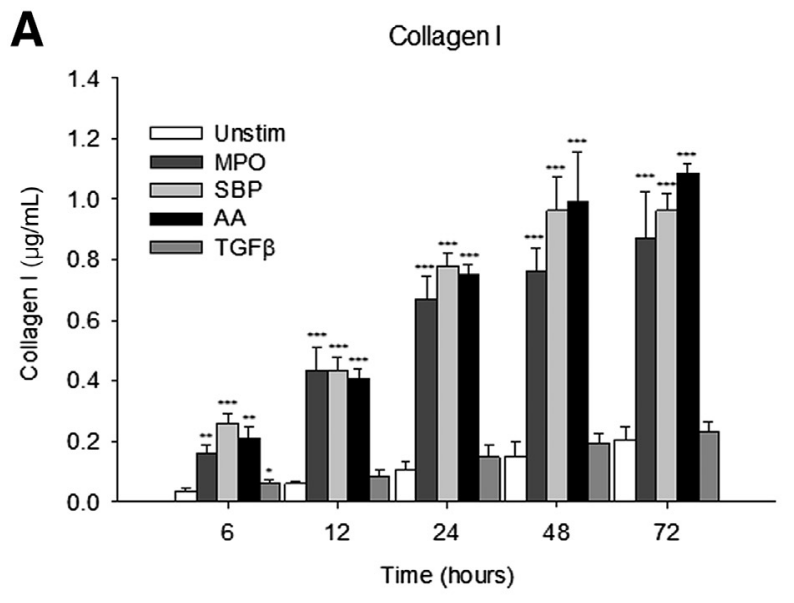

B

Collagen I $\propto 1 \mathrm{mRNA}$

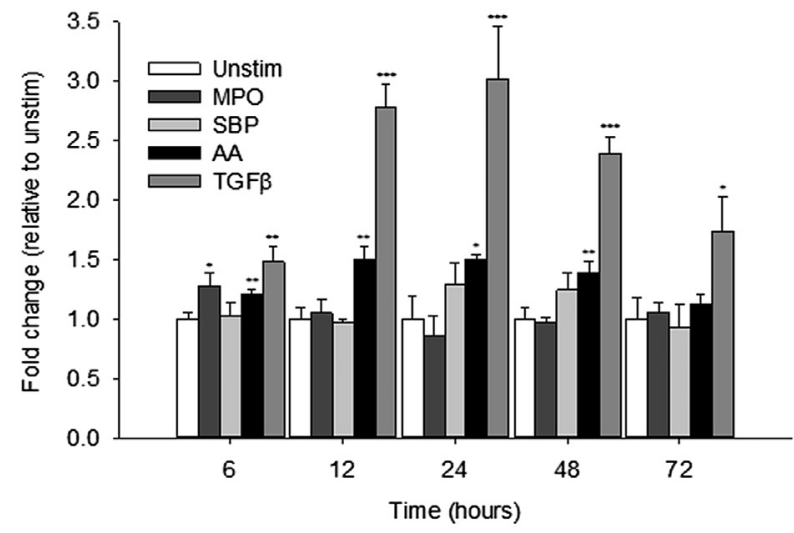

Figure 7 Peroxidases induce collagen I release without regulating collagen I $\alpha 1$ mRNA levels. A: Enzyme-linked immunosorbent assay detection of soluble collagen I levels in human foreskin fibroblast (HFF)-conditioned medium at the indicated time points on stimulation with $1.56 \mu \mathrm{g} / \mathrm{mL}$ myeloperoxidase (MP0), $1 \mu \mathrm{g} / \mathrm{mL}$ soybean peroxidase (SBP), $100 \mu \mathrm{mol} / \mathrm{L}$ ascorbic acid 2-phosphate (AA), or $10 \mathrm{ng} / \mathrm{mL}$ transforming growth factor (TGF)- $\beta 2$. Cells treated with Dulbecco's modified Eagle's medium (DMEM) alone (unstim) served as the baseline control at each time point. The levels of soluble collagen I are expressed as $\mu \mathrm{g} / \mathrm{mL}$. B: Quantitative real-time PCR analysis of the collagen I $\alpha 1$ mRNA expression (normalized to glyceraldehyde-3phosphate dehydrogenase) in HFFs at the indicated time points on stimulation with $1.56 \mu \mathrm{g} / \mathrm{mL} \mathrm{MP0,} 1 \mu \mathrm{g} / \mathrm{mL} \mathrm{SBP}, 100 \mu \mathrm{mol} / \mathrm{L} \mathrm{AA}$, or $10 \mathrm{ng} / \mathrm{mL}$ TGF- $\beta 2$. Cells treated with DMEM alone (unstim) served as the baseline control at each time point. The levels of collagen I $\alpha 1$ transcript are expressed as fold change, normalized so the average values of unstim at each time point were set to 1 . Statistical significance was calculated by two-tailed Student's $t$-test, with the various treatment groups compared to the DMEM alone (unstim) group at each time point. Each time course experiment was independently performed three times. Data are the means \pm SD of triplicate determinations for each time point. ${ }^{*} P<0.05,{ }^{*} P<0.01$, and ${ }^{*} * P<0.001$. 
both MPO and SBP increased the levels of collagen I detected in HFF-conditioned media after just 6 hours (Figure 7A). The amount of collagen I stimulated by these enzymes increased with time, reaching maximal levels between 48 and 72 hours. The profile of collagen I release stimulated by the peroxidases was virtually identical to that observed for AA, in terms of both magnitude and time dependency. In contrast, without AA supplementation, TGF- $\beta 2$ failed to induce a significant increase in collagen I release over the 72-hour time frame (Figure 7A). Real-time PCR analysis of collagen I $\alpha 1 \mathrm{mRNA}$ levels within these cells revealed that the robust increase in collagen I protein stimulated by the peroxidases was not associated with a corresponding increase in collagen I mRNA levels (Figure 7B). In contrast, TGF- $\beta 2$ clearly induced a time-dependent increase in collagen I $\alpha 1 \mathrm{mRNA}$, with a maximal threefold increase detected at 24 hours, with levels returning to baseline by 72 hours. Compared to TGF- $\beta$, AA induced a small, but significant, increase in collagen $I \alpha$ mRNA expression between 6 and 48 hours after stimulation, which is consistent with its established role as a profibrogenic factor that predominantly regulates collagen biosynthesis at a post-translational level. ${ }^{4,16}$

AA acts on cultured fibroblasts to promote efficient hydroxylation of procollagen, leading to the subsequent release of triple helical collagen from the cell that is thermally stable by nature. ${ }^{2}$ Our findings that peroxidases are capable of stimulating collagen I release by fibroblasts in a reaction that does not require AA suggest these enzymes are also likely to influence post-translational hydroxylation of procollagen I. It was, therefore, important to investigate whether collagen I released by peroxidase-treated cells in the absence of AA was similar biochemically to the collagen I released by fibroblasts stimulated with AA alone. We performed Western blot analysis of collagen I released by HFFs into the culture medium because gross differences in hydroxylation can be detected as changes in procollagen subunit mobility during gel electrophoresis. ${ }^{17}$ The data show both the bands corresponding to the collagen pro $\alpha 1$ (I) and pro $\alpha 2$ (I) subunits migrate at the same molecular weight irrespective of whether the cells were stimulated with AA alone or with peroxidase enzymes in the absence of AA (Figure 8A), indicating that no significant differences exist in the level of collagen hydroxylation.

To assess the thermal stability of collagen I released by fibroblasts on peroxidase treatment in the absence of AA, culture medium from HFFs stimulated with either AA or EPO was subjected to digestion using a mixture of trypsin and chymotrypsin over an increasing temperature range between $34^{\circ} \mathrm{C}$ and $42^{\circ} \mathrm{C}$, followed by gel electrophoresis and Western blot analysis for collagen I. The results clearly show that treatment of HFFs with either AA or EPO results in the release of collagen I with an identical Tm (midpoint of thermal transition) of $40^{\circ} \mathrm{C}$ (Figure $8 \mathrm{~B}$ ), suggesting that the collagen I released by peroxidase-treated cells in the absence of AA is fully or near fully hydroxylated and triple helical.

As the AA and peroxidase-mediated collagen I release profiles, Tm and electrophoretic mobilities were similar;
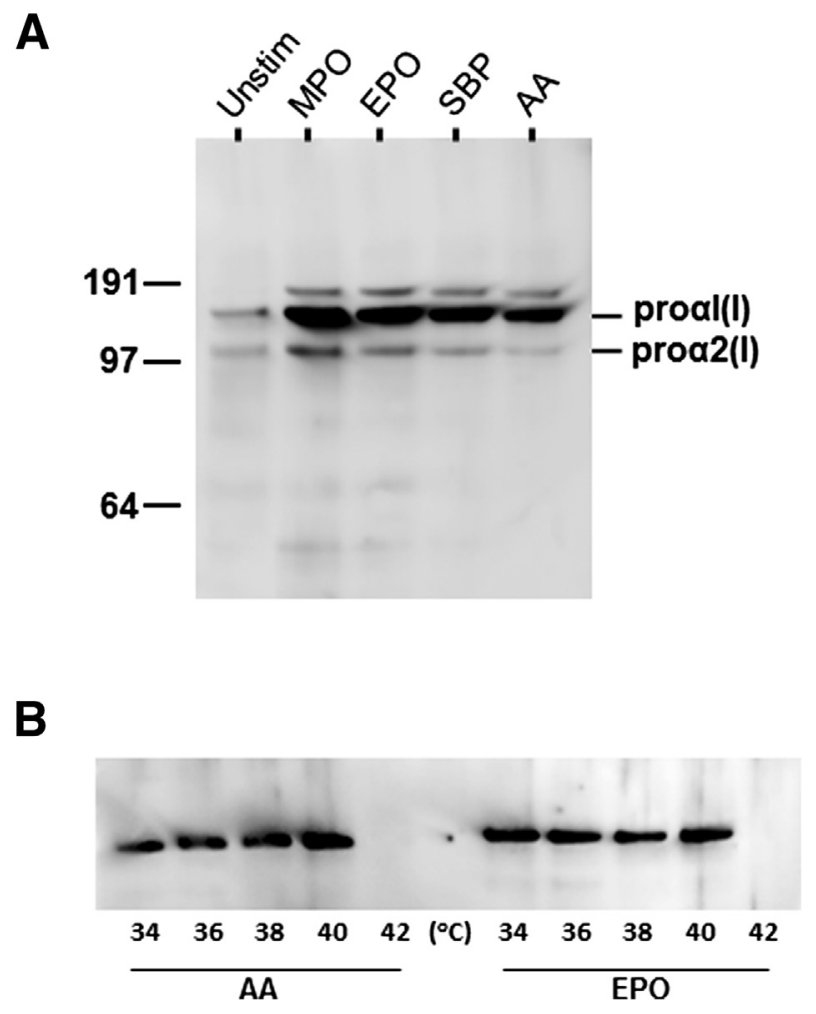

Figure 8 Western blot analysis of collagen I secreted by human foreskin fibroblasts (HFFs) after exposure to peroxidase enzymes or ascorbic acid 2-phosphate (AA). A: Western blot analysis of collagen I from culture medium of HFFs stimulated 72 hours with $1.56 \mu \mathrm{g} / \mathrm{mL}$ peroxidase [myeloperoxidase (MP0), eosinophil peroxidase (EPO), or soybean peroxidase (SBP)], $100 \mu \mathrm{mol} / \mathrm{L} \mathrm{AA}$, or Dulbecco's modified Eagle's medium (DMEM) alone (unstim). Bands corresponding to proa1(I) and proa2(I) and molecular weights $(\mathrm{kDa})$ are indicated. B: Western blot analysis of collagen I from culture medium of HFFs stimulated 72 hours with either $100 \mu \mathrm{mol} / \mathrm{L}$ AA or $1.56 \mu \mathrm{g} / \mathrm{mL}$ EPO and subsequently digested with a mixture of trypsin and chymotrypsin for 2 minutes at temperatures indicated.

further in vitro studies using cultured fibroblasts were conducted to establish whether peroxidases were also capable of regulating post-translational collagen I biosynthesis in a P4H-dependent manner. HFFs were stimulated with either MPO or EPO in the presence of dimethyloxalylglycine (DMOG), a cell-permeable structural analogue of $\alpha$-ketoglutarate, which acts as a competitive inhibitor of prolyl hydroxylases. ${ }^{18}$ As a positive control, cells stimulated with AA were also treated with DMOG to confirm if the release of collagen I was dependent on $\mathrm{P} 4 \mathrm{H}$-mediated hydroxylation. DMOG blocked the AA and also the peroxidaseinduced release of collagen I from HFFs in a dose-dependent manner, with complete inhibition occurring between 25 and 50 $\mu \mathrm{mol} / \mathrm{L}$ (Figure 9). The inhibitory effect of DMOG was not associated with a loss in cell viability (data not shown).

\section{Peroxidase Catalytic Activity Is Essential for Collagen I Biosynthesis}

When HFFs were stimulated with MPO or EPO in the presence of 4-amino-benzoic acid hydrazide (4-ABAH), an 


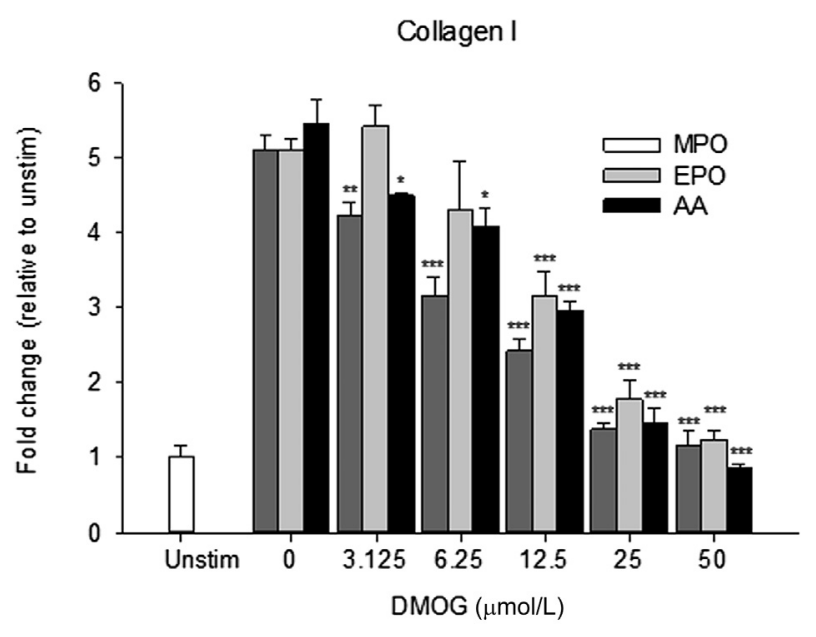

Figure 9 Inhibition of peroxidase-induced collagen I release by the prolyl hydroxylase inhibitor dimethyloxalylglycine (DMOG). Enzyme-linked immunosorbent assay detection of soluble collagen I levels in human foreskin fibroblast (HFF)-conditioned medium after cells were pretreated for 30 minutes with DMOG at the doses indicated, then stimulated by the addition of $5 \mu \mathrm{g} / \mathrm{mL}$ myeloperoxidase (MP0), $5 \mu \mathrm{g} / \mathrm{mL}$ eosinophil peroxidase (EPO), or $100 \mu \mathrm{mol} / \mathrm{L}$ ascorbic acid 2-phosphate (AA) for a further 72 hours. Soluble collagen I levels are expressed as fold change, normalized to the average values of cells treated with Dulbecco's modified Eagle's medium alone (unstim). Statistical significance was calculated using the two-tailed Student's $t$-test with the DMOG-treated groups compared to the treatment group without DMOG. Inhibition studies using DMOG were independently performed twice over the same dose range. Data are the means \pm SD of triplicate determinations. ${ }^{*} P<0.05,{ }^{*} P<0.01$, and ${ }^{*} * P<0.001$.

irreversible inhibitor of peroxidase enzymatic activity, ${ }^{19}$ a clear dose-dependent inhibition of collagen I release was observed over a 72-hour time period (Figure 10). In contrast, 4-ABAH over the same dose range had no impact on AAinduced collagen I release, confirming 4-ABAH was inhibiting the peroxidase catalytic activity and not the cellular collagen biosynthetic pathway. HFF exposure to increasing doses of $4-\mathrm{ABAH}$ up to $250 \mu \mathrm{mol} / \mathrm{L}$ had no impact on cellular viability over the duration of the experimental period (data not shown). These data confirm that the hemecontaining catalytic domain plays an essential role in MPOand EPO-mediated collagen I biosynthesis in fibroblasts.

\section{Fibroblasts Rapidly Bind and Internalize Peroxidase Enzymes}

To determine whether exposure of HFFs to MPO and EPO could promote cell surface binding and internalization of these enzymes, immunofluorescence localization studies were performed (Figure 11). The images clearly show that cultured dermal fibroblasts bind and rapidly internalize peroxidase enzymes. Both MPO and EPO accumulate on the cell surface within minutes of peroxidase exposure (Figure 11), whereas no staining was detected in peroxidase-untreated cells, confirming the specificity of the EPO and MPO immunostaining (data not shown). After 3 hours of peroxidase exposure, there was intense intracellular MPO and EPO staining, with both enzymes localizing to vesicle-like structures that have a distinct perinuclear distribution (Figure 11).

\section{Discussion}

Our data provide evidence, for the first time, that the peroxidase enzymes EPO and MPO regulate fibroblast migration and collagen I biosynthesis, offering a new and important insight into the causative association between inflammation and aberrant fibrotic conditions. For example, the intense deposition of EPO (originating from degranulating eosinophils) found only in the fibrotic connective tissue of human endometriosis specimens and not in normal proliferative or secretory endometrium directly implicates this peroxidase in the fibrotic sequel associated with this condition. ${ }^{9}$ Similarly, in the light of the results presented herein, MPO is significantly increased in bronchoalveolar lavage fluid taken from individuals with idiopathic pulmonary fibrosis ${ }^{20,21}$; however, elevated levels of both EPO and MPO have been detected in sputum of patients with chronic obstructive pulmonary disease. ${ }^{22}$ Moreover, Rudolph et $\mathrm{al}^{8}$ have provided clinical and experimental evidence, using MPO-deficient mice, that MPO acts as a profibrotic mediator in atrial fibrillation, although these authors postulated that the molecular mechanism underlying MPO-dependent atrial fibrosis was via regulation of matrix metalloproteinase enzymatic activity, rather than the regulation of collagen biosynthesis.

Peroxidase-mediated collagen biosynthesis by tumorassociated fibroblasts may also play an important role in

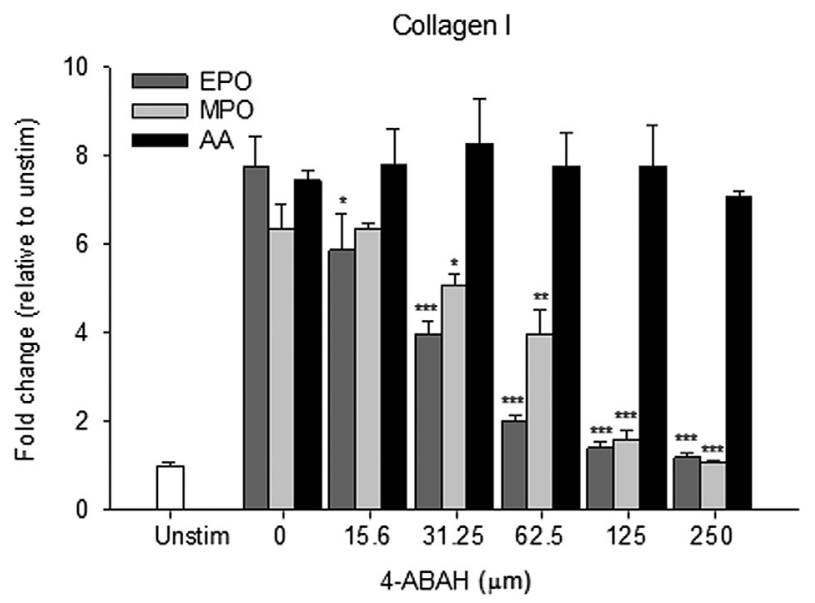

Figure 10 Inhibition of peroxidase-induced collagen I release by 4-aminobenzoic acid hydrazide (4-ABAH). Enzyme-linked immunosorbent assay detection of soluble collagen I levels in human foreskin fibroblast (HFF)conditioned medium after cells were pretreated for 30 minutes with 4-ABAH at the doses indicated, then stimulated by the addition of $5 \mu \mathrm{g} / \mathrm{mL}$ myeloperoxidase (MPO), $5 \mu \mathrm{g} / \mathrm{mL}$ eosinophil peroxidase (EPO), or $100 \mu \mathrm{mol} / \mathrm{L}$ ascorbic acid 2-phosphate (AA) for a further 72 hours. Soluble collagen I levels are expressed as fold change, normalized to the average values of cells treated with Dulbecco's modified Eagle's medium alone (unstim). Statistical significance was calculated using the two-tailed Student's $t$-test with the 4-ABAH-treated groups compared to the treatment group without 4-ABAH. Inhibition studies using 4$\mathrm{ABAH}$ were independently performed three times. Data are the means $\pm \mathrm{SD}$ of triplicate determinations. ${ }^{*} P<0.05,{ }^{* *} P<0.01$, and ${ }^{* * *} P<0.001$. 


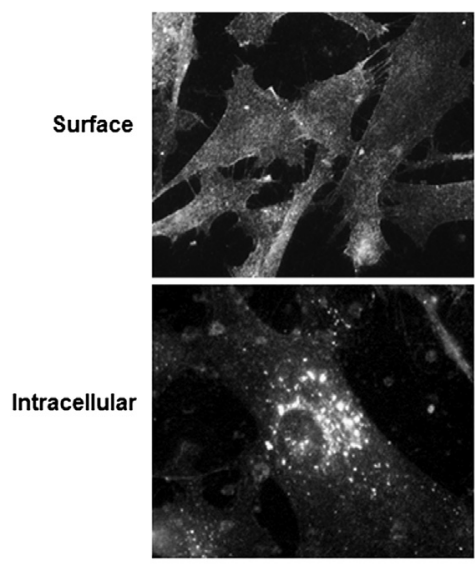

Anti-MPO

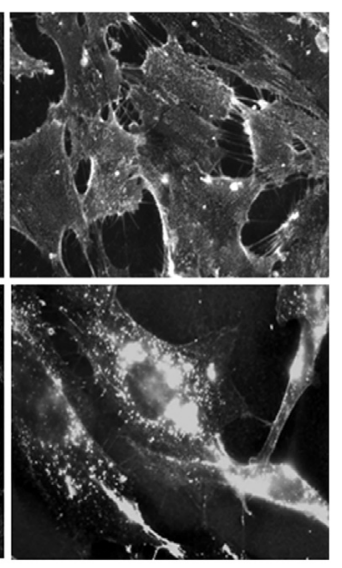

Anti-EPO
Figure 11 Localization of peroxidase distribution by indirect immunofluorescence. Cultured human foreskin fibroblasts were exposed to $1 \mu \mathrm{g} / \mathrm{mL}$ myeloperoxidase (MPO) or eosinophil peroxidase (EPO) in serumfree Dulbecco's modified Eagle's medium for either 20 minutes (surface) or 3 hours (intracellular). Cells were fixed, permeabilized (intracellular only), and stained for MPO and EPO localization, as described in Materials and Methods. Original magnification: $\times 40$ (surface images); $\times 63$ (intracellular images).

tumor progression and metastasis. Several reports have recently emerged showing MPO localization and enhanced catalytic activity to be associated with the early-stage development of both lung and breast tumors in mouse models, ${ }^{23-25}$ whereas $88 \%$ of human breast cancer biopsy specimens showed EPO deposits located primarily in the connective tissue stroma around and within the tumor. ${ }^{26}$ Our discovery that MPO and EPO can also regulate mammary and prostate stromal fibroblast collagen I biosynthesis strengthens the case that these enzymes potentially serve as therapeutic targets to prevent the rapid escalation in collagen I biosynthesis seen in pathological diseases, such as cancer, where inflammatory cell infiltration and peroxidase release are key features.

Our experimental data indicate that peroxidase enzymes do not stimulate fibroblast proliferation either under culture conditions or when injected intradermally into rats. These observations are contrary to those recently reported where MPO stimulated an increase in synovial fibroblast proliferation, as measured by intracellular bromodeoxyuridine incorporation. ${ }^{27}$ An important feature that may account for the discrepancy between our observations and those reported in synovial fibroblasts is that tumor necrosis factor $\alpha$, a well-recognized fibroblastic mitogenic factor, ${ }^{28}$ was also added in combination with MPO to promote proliferation of these cells. Whether MPO alone has the capacity to stimulate synovial fibroblast proliferation was not assessed.

Our mechanistic data from in vitro culture studies demonstrate that the peroxidase proteins induce a cellular response that is clearly distinct from TGF- $\beta$ in terms of collagen mRNA and protein expression. In contrast, the overall response elicited by the peroxidase proteins is not dissimilar to those generally reported for ascorbate. Our finding that exposure of fibroblasts to peroxidase proteins caused a robust increase in collagen I secretion without a corresponding increase in collagen I mRNA levels is consistent with previous findings reported after stimulation of human skin fibroblasts with ascorbate. ${ }^{16} \mathrm{AA}$ is known to function as an enzymatic cofactor for prolyl hydroxylase to promote post-translational collagen biosynthesis. ${ }^{2-4}$ Our data showing the inhibition of peroxidase-induced collagen I release by the prolyl hydroxylase inhibitor DMOG support our hypothesis that post-translational events are most likely to be affected by the peroxidases. Moreover, given that hydroxylation is an essential requirement for secretion of procollagen from the cell, we propose that peroxidase enzymes can substitute for AA at this point in the biosynthetic pathway to improve hydroxylation efficiency and the use of translated protein. Our results showing that in the absence of AA, collagen I released by peroxidase-treated fibroblasts has a $\mathrm{Tm}$ of $40^{\circ} \mathrm{C}$ add further support to this notion, indicating the collagen I is hydroxylated and in a thermally stable triple helical conformation.

We believe this important observation has previously been overlooked by others because AA is routinely added to fibroblast culture medium when examining collagen biosynthesis. When combined with AA, the stimulatory effects of peroxidase enzymes on fibroblast collagen release are masked (data not shown), suggesting that both agents target the same regulatory point in collagen biosynthesis.

Our data also confirm that peroxidase heme-containing catalytic domain plays an essential role in MPO- and EPOmediated collagen biosynthesis in fibroblasts. Both mammalian and plant-derived peroxidase enzymes consume hydrogen peroxide $\left(\mathrm{H}_{2} \mathrm{O}_{2}\right)$ as a substrate to generate multiple distinct intracellular reactive oxidant species. ${ }^{29}$ Cellular $\mathrm{H}_{2} \mathrm{O}_{2}$ is predominantly produced through dismutation of superoxide that is formed by the one-electron reduction of molecular oxygen in a reaction catalyzed by NADPH oxidase. ${ }^{30} \mathrm{H}_{2} \mathrm{O}_{2}$ is lipid soluble, can readily diffuse across cellular membranes, and is known to oxidize the $\mathrm{Fe}^{2+}$ bound to the prolyl hydroxylase enzyme to $\mathrm{Fe}^{3+}$ via the Fenton reaction, leading to inhibition of prolyl hydroxylase enzymatic activity and substrate hydroxylation. ${ }^{31}$ Our observation that cultured fibroblasts rapidly bind and internalize both MPO and EPO raises the distinct possibility that peroxidase enzymes regulate the reduction-oxidation-sensitive prolyl hydroxylase system by catalytically depleting cellular $\mathrm{H}_{2} \mathrm{O}_{2}$ levels. Although the precise mechanisms are unclear, it is conceivable that intracellular reactive oxidant species generated by peroxidases also contribute to collagen biosynthesis by acting as alternative electron donors to reactivate prolyl hydroxylase iron to the $\mathrm{Fe}^{2+}$ state in the absence of AA. Most known reactive species generated by peroxidases are short lived and produced at low levels, making the task of identifying the exact oxidant species capable of regulating $\mathrm{P} 4 \mathrm{H}$ enzymatic activity and collagen biosynthesis a difficult one.

In conclusion, our novel findings, coupled with those previously reported by others, ${ }^{8}$ suggest that the peroxidase enzymes MPO and EPO are likely to regulate multiple 
cellular processes involved in collagen ECM regeneration, including fibroblast recruitment, collagen biosynthesis, and modulation of matrix metalloproteinase activity. The convergent outcome of these multiple mechanisms strongly suggests that these enzymes play an important role not only in normal tissue repair, but also in the progression of disease states where infiltrating inflammatory cells are known to deposit peroxidases.

\section{Acknowledgments}

Dr. Pritinder Kaur (Peter Mac Callum Institute, Melbourne, VIC, Australia) provided human foreskin fibroblasts; Dr. John Greenwood (Royal Adelaide Hospital, Adelaide, SA, Australia) provided adult dermal fibroblasts; Dr. Wendy Ingman (The University of Adelaide, Adelaide, SA, Australia) provided human mammary gland-derived fibroblasts; and Dr. Damien Leach (The University of Adelaide) provided human prostate stromal fibroblasts.

\section{References}

1. Peterkofsky B: Ascorbate requirement for hydroxylation and secretion of procollagen: relationship to inhibition of collagen synthesis in scurvy. Am J Clin Nutr 1991, 54:1135S-1140S

2. Myllyharju J, Kivirikko KI: Collagens and collagen-related diseases. Ann Med 2001, 33:7-21

3. Canty EG, Kadler KE: Procollagen trafficking, processing and fibrillogenesis. J Cell Sci 2005, 118:1341-1353

4. Kivirikko KI, Myllylä R, Pihlajaniemi T: Protein hydroxylation: prolyl 4-hydroxylase, an enzyme with four cosubstrates and a multifunctional subunit. FASEB J 1989, 3:1609-1617

5. Parsons KK, Maeda N, Yamauchi M, Banes AJ, Koller BH: Ascorbic acid-independent synthesis of collagen in mice. Am J Physiol Endocrinol Metab 2006, 290:E1131-E1139

6. Nishida H, Kurahashi T, Saito Y, Otsuki N, Kwon M, Ohtake H, Yamakawa M, Yamada K, Miyata S, Tomita Y, Fujii J: Kidney fibrosis is independent of the amount of ascorbic acid in mice with unilateral ureteral obstruction. Free Radic Res 2014, 48:1115-1124

7. Klebanoff SJ: Myeloperoxidase: friend or foe. J Leukoc Biol 2005, 77 : 598-625

8. Rudolph V, Andrie RP, Rudolph TK, Friedrichs K, Klinke A, HirschHoffmann B, Schwoerer AP, Lau D, Fu X, Klingel K, Sydow K, Didié M, Seniuk A, von Leitner E, Szoecs K, Schrickel JW, Treede H, Wenzel U, Lewalter T, Nickenig G, Zimmermann W, Meinertz T, Böger RH, Reichenspurner H, Freeman BA, Eschenhagan T, Ehmke H, Hazen SL, Willems S, Baldus S: Myeloperoxidase acts as a profibrotic mediator of atrial fibrillation. Nat Med 2010, 16:470-474

9. Blumenthal RD, Samoszuk M, Taylor AP, Brown G, Alisauskas R, Goldenberg DM: Degranulating eosinophils in human endometriosis. Am J Pathol 2000, 156:1581-1588

10. Forbes E, Murase T, Yang M, Matthaei KI, Lee JJ, Lee NA, Foster PS, Hogan SP: Immunopathogenesis of experimental ulcerative colitis is mediated by eosinophil peroxidase. J Immunol 2004, 172:5664-5675

11. Stingl J, Emerman JT, Eaves CJ: Enzymatic dissociation and culture of normal human mammary tissue to detect progenitor activity. Methods Mol Biol 2005, 290:249-263

12. Li Y, Li CX, Ye H, Chen F, Melamed J, Peng Y, Liu J, Wang Z, Tsou HC, Wei J, Walden P, Garabedian MJ, Lee P: Decrease in stromal androgen receptor associates with androgen-independent disease and promotes prostate cancer cell proliferation and invasion. $\mathrm{J}$ Cell Mol Med 2008, 12:2790-2798
13. Bruckner P, Prockop D: Proteolytic enzymes as probes for the triplehelical conformation of procollagen. Anal Biochem 1981, 110: 360-368

14. Greenwood JE, Dearman BL: Comparison of a sealed, polymer foam biodegradable temporizing matrix against Integra ${ }^{\circledR}$ dermal regeneration template in a porcine wound model. J Burn Care Res 2012, 33: $163-173$

15. Lettmann S, Bloch W, Maaß T, Niehoff A, Schulz JN, Eckes B, Eming SA, Bonaldo P, Paulsson M, Wagener R: Col6a1 null mice as a model to study skin phenotypes in patients with collagen VI related myopathies: expression of classical and novel collagen VI variants during wound healing. PLoS One 2014, 9:1-9

16. Chan D, Lamande SR, Cole WG, Bateman JF: Regulation of procollagen synthesis and processing during ascorbate-induced extracellular matrix accumulation in vitro. Biochem J 1990, 269:175-181

17. Cheah KS, Grant ME, Jackson DS: Translation of type II procollagen mRNA and hydroxylation of the cell-free product. Biochem Biophys Res Commun 1979, 91:1025-1031

18. Baader E, Tschank G, Baringhaus K, Burghard H, Günzler V: Inhibition of prolyl 4-hydroxylase by oxalyl amino acid derivatives in vitro, in isolated microsomes and in embryonic chicken tissues. Biochem J 1994, 300:525-530

19. Kettle AJ, Gedye CA, Winterbourn CC: Mechanism of inactivation of myeloperoxidase by 4-aminobenzoic acid hydrazide. Biochem J 1997 , 321:503-508

20. Hällgren R, Bjermer L, Lundgren R, Venge P: The eosinophil component of the alveolitis in idiopathic pulmonary fibrosis: signs of eosinophil activation in the lung are related to impaired lung function. Am Rev Respir Dis 1989, 139:373-377

21. Stijn W, Verleden SE, Vanaudenaerde BM, Wynants M, Dooms C, Yserbyt J, Somers J, Verbeken EK, Verleden GM, Wuyts WA: Multiplex protein profiling of bronchoalveolar lavage in idiopathic pulmonary fibrosis and hypersensitivity pneumonitis. Ann Thorac Med 2013, 8:38-45

22. Keatings VA, Barnes PJ: Granulocyte activation markers in induced sputum: comparison between chronic obstructive pulmonary disease, asthma, and normal subjects. Am J Respir Crit Care Med 1997, 155: 449-453

23. Zhang N, Francis KP, Prakash A, Ansaldi D: Enhanced detection of myeloperoxidase activity in deep tissue through luminescent excitation of near-infrared nanoparticles. Nat Med 2013, 19:500-550

24. Alshetaiwi HS, Balivada S, Shresha TB, Pyle M, Basel MT, Bossmann SH, Troyer DL: Luminol-based bioluminescence imaging of mouse mammary tumors. J Photochem Photobiol B 2013, 127:223-228

25. Rymaszewski AL, Tate E, Yimbesalu JP, Gelman AE, Jarzembowski JA, Zhang H, Pritchard KA, Vikis HG: The role of neutrophil myeloperoxidase in models of lung tumor development. Cancers (Basel) 2014, 6: $1111-1127$

26. Samoszuk MK, Nguyen V, Gluzman I, Pham JH: Occult deposition of eosinophil peroxidase in a subset of human breast carcinomas. Am J Pathol 1996, 148:701-706

27. Odobasic D, Yang Y, Muljadi RCM, O’Sullivan KM, Kao W, Smith M, Morand EF, Holdsworth SR: Endogenous myeloperoxidase is a mediator of joint inflammation and damage in experimental arthritis. Arthritis Rheumatol 2014, 66:907-917

28. Thornton SC, Por SB, Penny R, Richter M, Shelley L, Breit SN: Identification of the major fibroblast growth factors released spontaneously in inflammatory arthritis as platelet derived growth factor and tumour necrosis factor-alpha. Clin Exp Immunol 1991, 86:79-86

29. Davies MJ, Hawkins CL, Pattison DI, Rees MD: Mammalian heme peroxidases: from molecular mechanisms to health implications. Antioxid Redox Signal 2008, 10:1199-1234

30. Genestra M: Oxyl radicals, redox-sensitive signalling cascades and antioxidants. Cell Signal 2007, 19:1807-1819

31. Gerald D, Berra E, Frapart YM, Chan DA, Giaccia AJ, Mansuy D, Pouyssegur J, Yaniv M, Mechta-Grigoriou F: JunD reduces tumor angiogenesis by protecting cells from oxidative stress. Cell 2004, 118: 781-794 